\title{
Quantum Dots in Biomedical Research
}

\author{
Adriana Fontes, Rafael Bezerra de Lira, \\ Maria Aparecida Barreto Lopes Seabra, Thiago Gomes da Silva, \\ Antônio Gomes de Castro Neto and Beate Saegesser Santos
}

Additional information is available at the end of the chapter

http://dx.doi.org/10.5772/50214

\section{Introduction}

Quantum dots (QDs) are colloidal semiconductor nanocrystals which have unique optical properties due to their three dimensional quantum confinement regime. The quantum confinement may be explained as follows: in a semiconductor bulk material the valence and conduction band are separated by a band gap (Eg). After light absorption, an electron $\left(e^{-}\right)$ can be excited from the valence band to the conduction band, leaving a hole $\left(\boldsymbol{h}^{+}\right)$in the valence band. When the electron returns to the valence band, fluorescence is emitted. During the small time scale of the light absorption the $\boldsymbol{e}^{-}$and $\boldsymbol{h}^{+}$perceive one another and do not move so independently due to Coulomb attraction (Brus, 1984). The $\boldsymbol{e}^{-}-\boldsymbol{h}^{+}$pair may be observed as an Hydrogen-like species called exciton and the distance between them is called the exciton Bohr radius (ав). When the three dimensions of the semiconductor material are reduced to few nanometers and the particles become smaller than the Bohr radius, one can say that they are in quantum confinement regimen and in this situation these nanoparticles are named quantum dots (QDs). For example, the exciton Bohr radius of CdS and CdSe bulk materials presents a size of $а в=3$ to $5 \mathrm{~nm}$.

In this way, QDs can be defined as colloidal particles made of semiconductor materials with diameters ranging typically from 2 to $10 \mathrm{~nm}$. The semiconductor particle (named "core") is usually coated by a layer of another semiconductor material (named "shell") which in general has a greater band gap than the band gap of the core rendering excellent optical properties. The QDs' core is responsible for the fundamental optical properties (i.e. light absorption and emission) and the shell is used to passivate the surface of the core with the goal to improve its optical properties and reduce chemical attack. The shell separates physically the optically active core from its surrounding medium (Dabbousi et al., 1997; Santos et al., 2008a) as depicted in Figure 1. As a consequence, the nanoparticles' optical properties become less sensitivity to changes induced, for example, by the presence of 
oxygen or $\mathrm{pH}$ in the local environment. At the same time, the shell reduces the number of surface dangling bonds, which can act as trap states for electrons and minimize the QDs fluorescence efficiency.

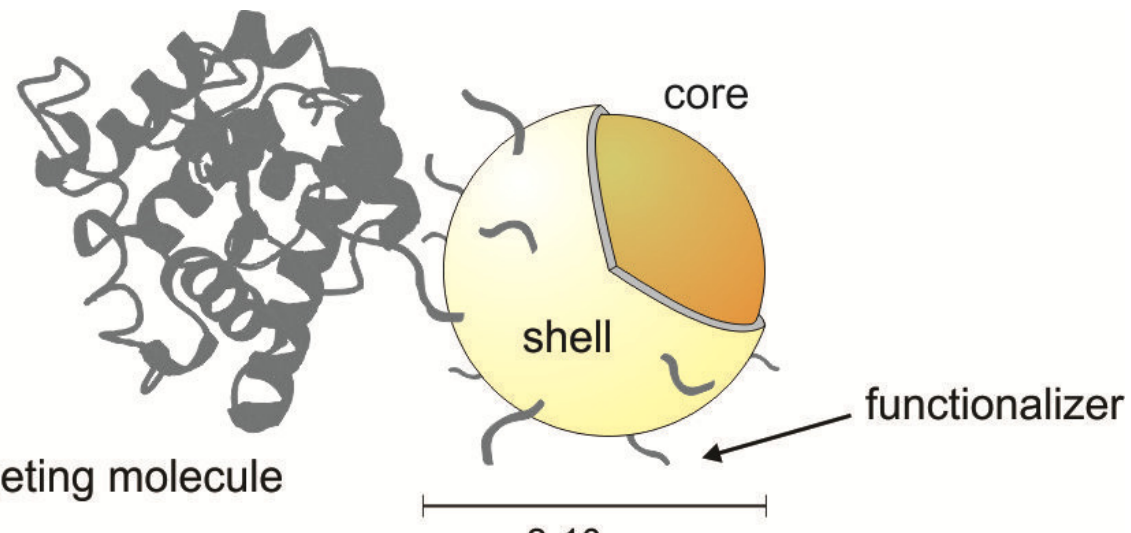

$2-10 \mathrm{~nm}$

Figure 1. A schematic representation of a functionalized core-shell quantum dot bound to a biomolecule.

For biomedical purposes, in which fluorescence in the visible region is usually required, both core and shell are composed of elements from the II B and VI A groups of the Periodic Table. The major examples are CdSe/ZnS, CdTe/CdS and ZnSe/ZnS QDs (Dabbousi et al., 1997; Santos et al., 2008a). Most QDs crystallize either in the cubic zinc blend or in the hexagonal wurtzite type structure (Yeh et al., 1992).

In nanosized regime many QDs' physico-chemical properties are different from those of the same bulk materials. Since QDs are fluorescent nanoparticles, an example of these changes is the shift of the emission color according to the particle size. In this case, QDs made from the same material, but with different sizes, can present fluorescence light emission in different spectral regions (from the ultraviolet to the infrared light) as represented in Figure 2. This is a consequence of QDs energy level discretization and also of the QDs band gap energy changes according to their size. After absorption, electrons come back to valence band and QDs emission is proportional to the band gap energy. As smaller the QDs are, the higher is the band gap energy and more towards to the blue end is the emission (since the energy is inversely proportional to the wavelength of the light).

Another observed feature for these systems is that the QDs' absorption bands are broad and extend up to the UV region, as observed in Figure 3 (A). The first peak (located at greater wavelength) represents an exciton formed by transitions between discrete states. The width of the first absorption band is related to the size dispersion of the nanoparticles and can give us information about the QDs' average size and nanoparticles concentration (Santos et al., 2008a). On the other hand, the width of the emission spectrum is related to the presence of crystal defects which result in discreet electronic states between the conduction and the valence band. These new electronic states displace the emission towards to the red and broaden the emission band and is related to the passivation shell. 


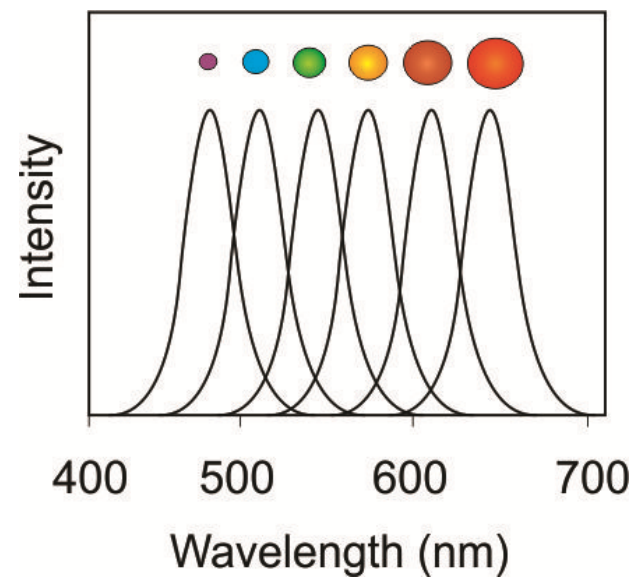

Figure 2. Emission spectra as a function of size for the same quantum dot material. The colored spheres represent the size decrease of the particles.

\section{A}

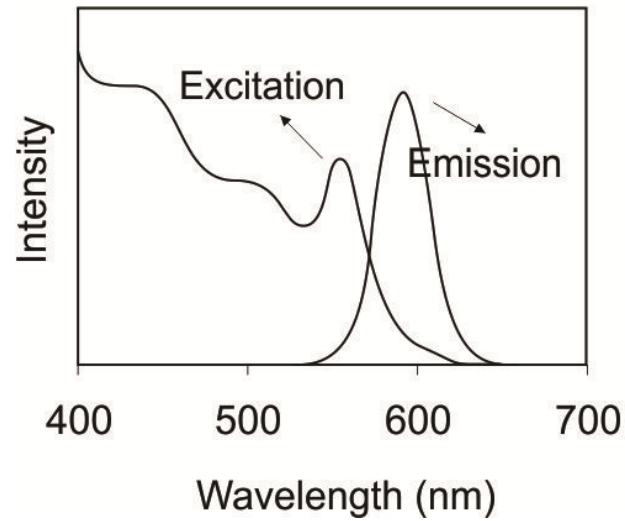

B

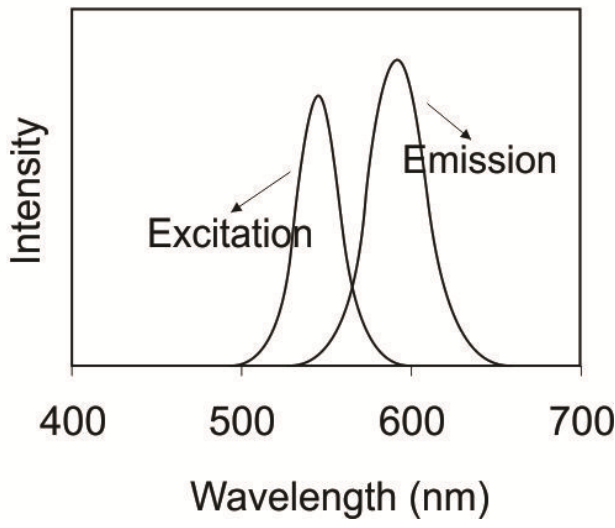

Figure 3. Characteristic absorption and emission band profile of (A) QDs colloidal suspension (A) and (B) a typical organic fluorophore (B).

The QDs' physico-chemical properties have offered considerable advantages and complementary characteristics over the conventional fluorescent dyes. Besides the size tunable emission discussed before, compared to organic fluorophores, the major advantages offered by QDs are:

1. A broad absorption band (Fig. 3A), allowing a flexible cross section for multiphoton microscopy and as well as for Fluorescence Energy Transfer (FRET) processes (Fig. 3A and B compare the characteristic absorption and emission band profiles of QDs and organic fluorophores).

2. An active surface for chemical conjugation. QDs can be conjugated to a variety of proteins or antibodies and become inorganic-biological hybrids nanoparticles that 
combine characteristics of both materials, that is, the fluorescence properties of QDs with the biochemical functions of the attached biomolecules (Fig. 1).

3. High resistance to photobleaching: the most important advantage of QDs over organic dyes allowing long term observation of these fluorescent nano-probes.

Colloidal QDs can be synthesized in organic or aqueous medium. When compared to organometallic routes, water-based QDs syntheses are cheaper, less toxic and intrinsically biocompatible to applications in biomedical fields (Santos et al., 2008a). The colloidal synthesis generally involves several consecutive stages: (i) nucleation from an initially homogeneous solution, (ii) growth of the preformed crystal nuclei into isolated particles, reaching the desired size from the reaction mixture and (iii) post preparative treatments, such as colloidal purification, size precipitation and UV light exposure.

During the colloidal synthesis QDs end up coated by organic or inorganic molecules (called surfactants or stabilizers), which keep the nanocrystals away from each other preventing agglomeration and precipitation (Brus, 1984; Santos et al., 2008a) (Figure 1). In some cases, as for CdTe QDs for example, the surfactant molecules may also act as precursors of the passivation shell (Menezes et al., 2005). For the direct aqueous synthetic procedures the main classes of organic molecules used as surfactants are alkyl-thiol molecules such as mercaptopropionic acid - MPA, mercaptoacetic acid - MAA and mercaptosuccinic acid MSA, Dihydrolipoic acid - DHLA, cysteine - CYS, cysteamine - CYSAM and different mercaptodithiols. The carboxyl, thiol or amine terminals of these molecules can be used as chemical bridges to conjugate biomolecules (such as proteins and biopolymers) which confer more specificity for biological applications. The chemical binding of such biomolecules to the surface of the QDs is a process defined as bioconjugation. It can be accomplished by simple adsorption (of stabilizing agent such as: MPA, MSA or cysteine) to the biomolecule or by covalent attachment. Currently, bioconjugation occurs between carboxyl-amine (through EDC and Sulfo-NHS) groups, amine-amine (by glutaraldehyde), disulfide bonds and streptavidin-biotin interactions (Goldman et al., 2002).

For the non-aqueous synthetic routes, nucleation and growth of QDs occur in the solution phase in the presence of organic surfactant molecules, which dynamically adhere to the surface of growing crystals. Typical surfactants include long-chain carboxylic and phosphonic acids (e.g., oleic acid and n-octadecylphosphonic acid), alkanethiols (e.g., dodecanethiol), alkyl phosphines, alkylphosphine oxides (classical examples are trioctylphosphine, TOP, and trioctylphosphine oxide, TOPO), and alkylamines such as hexadecylamine (Yin \& Alivisatos, 2005). In order to be applied to biological systems as active fluorophores these nanocrystals must be extracted from the organic phase to an aqueous phase. An alternative method of dispersing non-aqueous QDs is to form a hydrophilic coating that carries along with it a layer of hydration consisting of hydrogenbonded water molecules. This often is accomplished by using hydroxyl bearing polymers or Polyethylene glycol (PEG) modifications. These also prevent aggregation due to the high energy needed to remove the bound water layer. 


\section{Applications of quantum dots in biomedical sciences}

Since the first mention in the literature, in 1998, QDs have been studied extensively and the applications of these fluorescent nanocrystals range from imaging fixed and live cells all the way to fluoroimmunoassays rendering innovative diagnostic methodologies (Bruchez Jr. et al., 1998; Chan \& Nie, 1998). QDs have been used in many different studies, such as a probe in DNA hybridization, in receptor mediated endocytosis, monitoring of parasite metabolism and visualization of tissue and cellular structures in real time. Due to their photostability and low cytotoxicity the QDs are starting to be used as fluorophores for in vivo applications, but there is still a great discussion about their safe use. When injected in the initial stage of embryonic development of Xenopus embrios, for instance, the QDs demonstrated to be stable, non-toxic and resistant to photobleaching (Dubertret et al., 2002). This experiment also showed its potential in monitoring the development and cellular differentiation processes that occur during embryogenesis. The use of QDs as fluorophores is important for the real time diagnosis of tumors. Preliminary experiments with QDs emitting in the near infrared conducted in animals have shown promising results in the sensitive detection of cancerous tumors and in vivo systems (Cai et al., 2006; Gao et al., 2010). The prospects of the applications of QDs, especially those free of heavy metals such as zinc based QDs, make them even more promising for its current use in the near future. Moreover, cells labeled with QDs can be injected in small animals and the fluorescence can be used to follow a particular pathway in the organism, such as the carcinogenesis process, helping to understand the process and discover new kinds of treatments (Noh et al., 2008).

\subsection{Quantum dots as fluorophores for imaging and detection purposes}

\subsubsection{Non-specific labeling}

The staining of a biological sample can occur even when the reporting probe is not designed to interact with a specific molecule. Untargeted labeling of the probe with the (biological) material is defined as a non-specific interaction, and can be usually mediated by hydrophobic and/or electrostatic interactions between the surface molecules of the particles with molecules in suspension or on the anchoring surface such as cellular plasma membrane or even by internalization process (Biju et al., 2010).

In the past years, when the use of QDs in biomedical research was still at the beginning, passive labeling (simple staining of biological samples) was of great interest since researchers aimed to study the probe itself as a potential dye. In such applications, labeling could give information about bioavailability and more importantly about the optical properties of these nanoparticles in biological conditions. It has been shown that the simple incubation with a biological specimen may have the potential to stain it, revealing its structural features or even their biological behavior. We observed this feature for instance in the non-targeted glutaraldehyde-capped $\mathrm{CdS} / \mathrm{Cd}(\mathrm{OH})_{2}$ QDs staining of different neural cell lines, normal and cancerous cells (Santos et al., 2008b) as demonstrated in the staining pattern observed in Figure $4(\mathrm{~A}-\mathrm{D})$. For these systems the unrestricted labeling/internalization allows the identification of minor details of the cellular architecture, such as cell-cell contacts, axons and 
intracellular organelles, as shown on the images of Fig. 4A and Fig. 4B. Moreover, these QDs are taken up at different rates depending on cellular stage as for normal glial or glioblastoma cells (Farias et al., 2006) - Figures 4C and 4D, respectively. Therefore, passive labeling can be a useful strategy when one aims to label the whole biological sample or to study differences in the behavior of normal versus cancer cells in diagnostic purposes.

\subsubsection{Internalization of quantum dots by live cells}

In general, the binding of non-targeted particles with living cells results in internalization of the particles. This process may be accomplished by different routes, which depend either on the particle properties (size, shape, surface functionalization, surface charge and the combination of these properties) or on the cell type (i.e. lineage, metabolic state, cell cycle stage, normal or cancerous cells). The first assumption was that the main internalization process resulted from endocytosis. One of the first reports to show that internalization of these nanoparticles occurs by endocytosis was described by Jaiswal et al. (Jaiswal et al., 2003), where human cancer (HeLa) cells and Dictyostelium discoideum amoeba cells internalize negatively-charged DHLA-capped QDs, a process inhibited by low temperature treatment and co-localized with endosome markers.

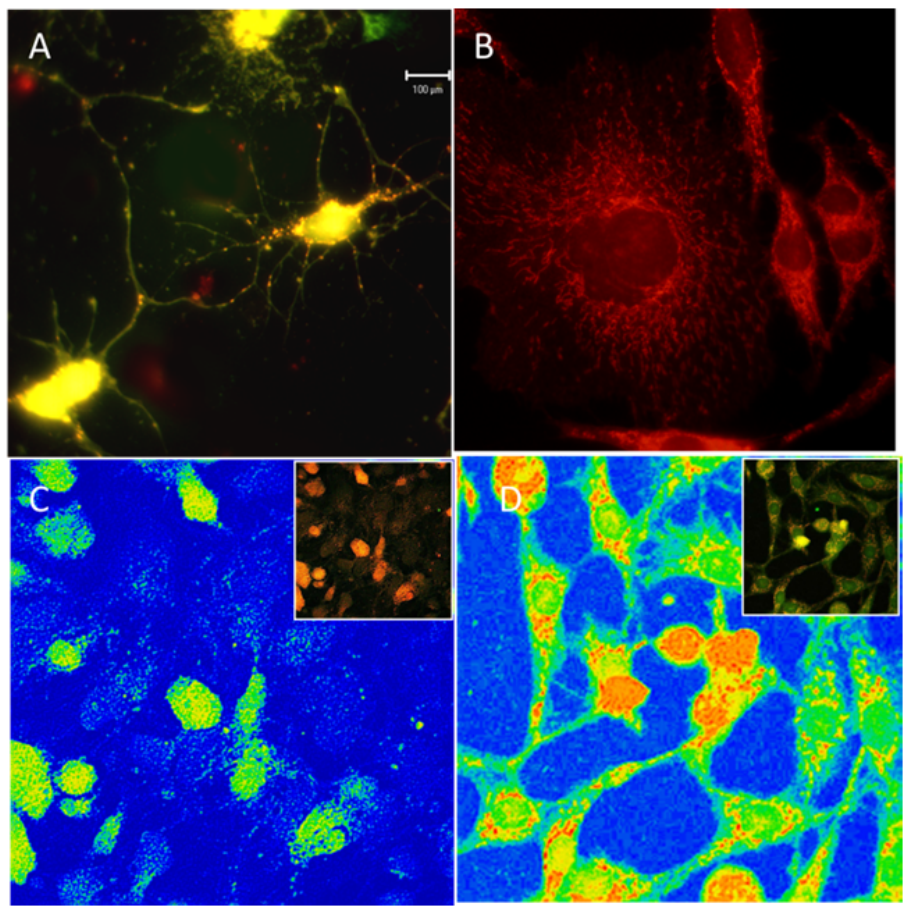

Figure 4. Non-targeted glutaraldehyde-capped $\mathrm{CdS} / \mathrm{Cd}(\mathrm{OH})_{2}$ labeling of live neuron live cells $(\mathrm{A})$ and live glioblastoma cells (B). It is possible to observe the cell body and axons in living neurons and intravesicular structures in glioblastomas. Intensity map images of glial (C) and glioblastomas (D) incubated for three minutes with these QDs. Insets are the corresponding fluorescence images. (Santos et al., 2008a). 
Molecule specific endocytosis is known as receptor-mediated endocytosis which are clathrin or caveolae-mediated endocytosis, or clathrin/caveolae independent endocytosis. It is probably the major pathway where QDs are uptaken by cells. It seems that lipid rafts localized within the plasma membrane plays an important role in the QDs uptake as well. These rafts provide a support for the assembly of many receptors, adaptors as well as proteins involved in a signaling complex such as caveolae and clathrin. (Nichols, 2003a; Nichols 2003b)

In 2011, Maysinger and collaborators synthesized QDs with almost the same hydrodynamic size (between 8-10 nm) and functionalized with different short ligands such as cysteine, cysteamine, dihydrolipoic acid and mercaptopropionic acid (Al-Hajaj et al, 2011). These QDs were tested in human embryonic kidney cells (Hek 293) and human heptocellular carcinoma cells (Hep G2) in order to achieve information about these QDs uptake and elimination. They showed that most of the QDs with the same size but different surface properties were uptaken through lipid raft-mediated endocytosis with the contribution of the $\mathrm{X}_{\mathrm{AG}}$ transport system (responsible for the carrier-mediated $\mathrm{Na}(+)$-independent transport of anionic amino acids such as glutamate and aspartate across the plasma membrane of cells) which takes up cysteine, glutamate and aspartate. The contribution of a P-glycoprotein transporter on QD efflux was also demonstrated during the experiments. Figure 5 shows the hypotheses about QDs internalization and elimination.

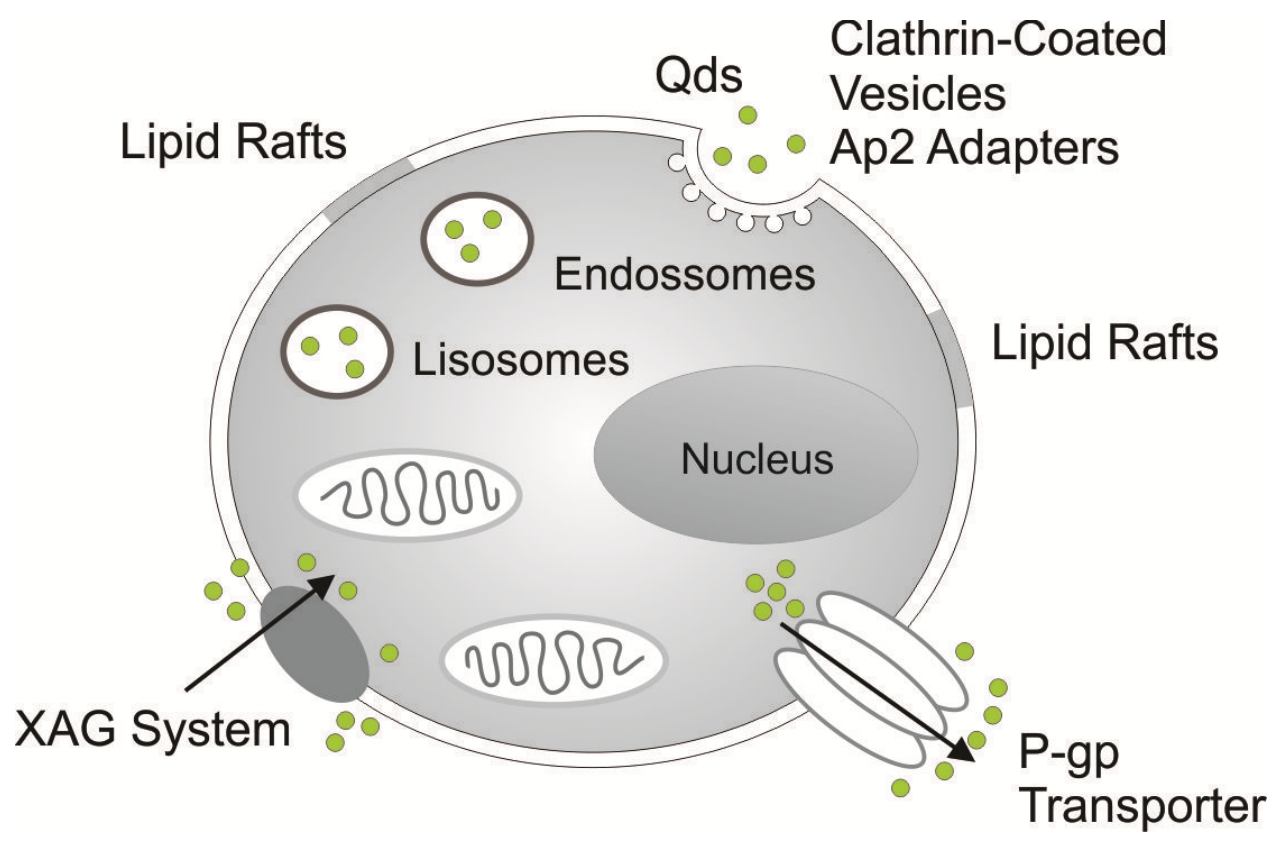

Figure 5. Representation of all the cell signaling mechanisms Studied by using QDs (Al-Hajaj et al, 2011).

These results corroborated with those obtained from Chan's (Jiang et al., 2008), where they showed the size dependent internalization of particles using both pathways clathrin- and caveolae- mediated endocytosis. It has been shown that particles with a diameter of $d=40-$ 
$50 \mathrm{~nm}$ are endocytosed more efficiently than those larger or smaller (Jiang et al., 2008). Sizes also dictates the final location of the particles (i.e. cytosol, nucleus), being able or not to cross their natural cellular barriers (Williams et al., 2009), which is on the other hand cell-type dependent (Williams et al., 2009).

However, QDs internalization by cells not only depends on their size. Although size is an important parameter, charge is thought as one of the most important parameter controlling cell-QD interactions (Conroy et al., 2008). An interesting finding of charge-mediated internalization and interactions with intracellular structures was found by Conroy et. al. (Conroy et al., 2008), who demonstrated that these carboxyl-coated (negative) QDs but not amine-coated (positive) are able to enter macrophage-like cells and bound nuclear structures rich in the positive histone proteins. In fact, such interactions were sufficiently strong to change QDs' optical and colloidal properties even in cell-free conditions (Conroy et al., 2008).

Lira et al have recently shown that even in the same cell population, carboxyl-coated QDs have differential access to intracellular compartments and when they reach the nucleus, they actually bind nuclear/nucleolar structures, as shown in Figure 6 for permeabilized humanderived peripheral blood cells (Lira et al., 2012). Figure 6 shows that the intracellular localization of these carboxyl-QDs for same cell population may differ from cell to cell. Depending on the cell, QDs could or not reach the nucleus (square 1 and 2, respectively). As will be discussed, the surface charge plays a critical role on such interactions. Although the internalization efficiency is significantly higher for positively-charged materials due to the

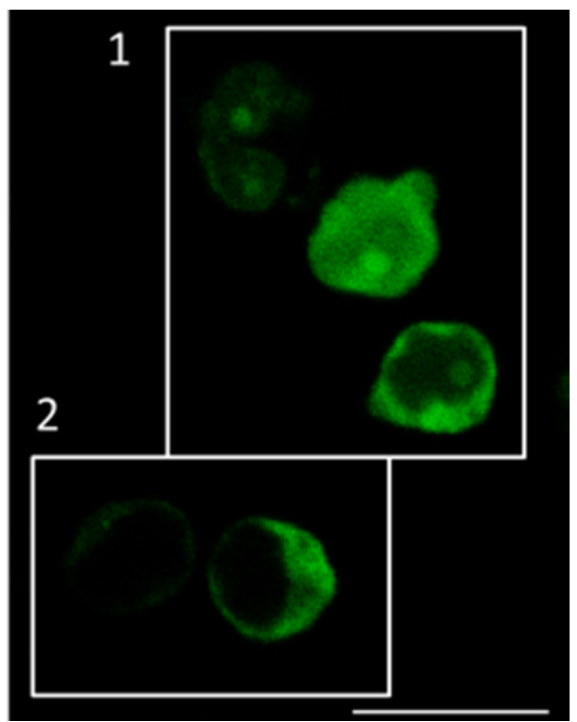

Figure 6. Non-specific labeling of fixed peripheral blood mononuclear cells. The image shows an optical field where CdTe/CdS QDs can reach only the cytoplasm (square 2) or can cross the nuclear membrane and reach the nucleus (square 1). In the nucleus, these nanoparticles bind with high affinity nuclear structures such as nucleoli (Lira et al., 2012). 

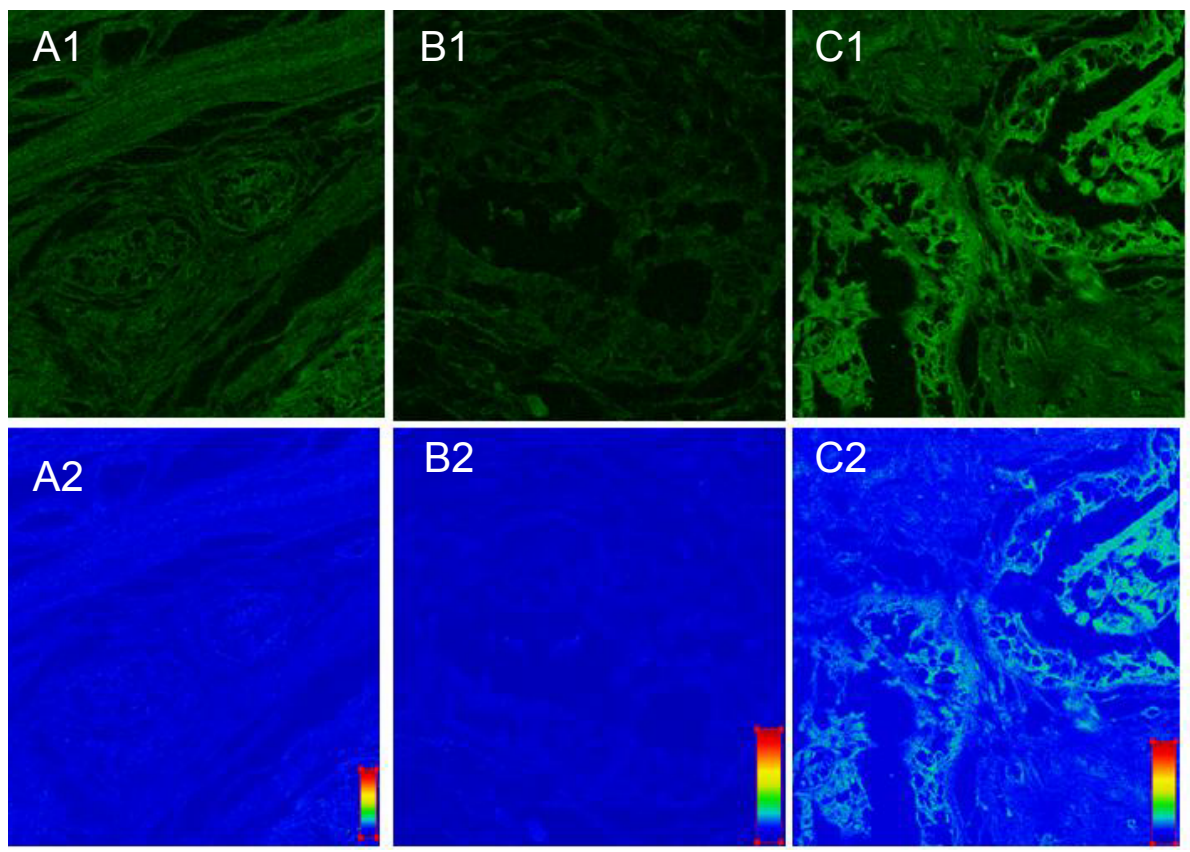

Figure 7. Human mammary tissue diagnosed as Fibroadenoma (Fib). (A1) Fib treated with Evan's Blue solution (EB); (B1) Fib incubated with QDs diluted in EB (QD-FIB-EB); (C1) Fib incubated with QD-ConA conjugate diluted in EB (QD-Con-A-FIB-EB). A2, B2 and C2 are the intensity maps of A1, B1 and C1, respectively. The bright pattern observed in (1c) is related to regions of high glucose/mannose expression in the tissue (Santos et al., 2006).

interactions with the negative cell surface, it is believed that cationic sites on the negatively charged cell surface can mediate the interaction of negative nanomaterials (Ghinea et al., 2009) eventually leading to internalization by cells.

\subsubsection{Some examples of specific labeling}

The capacity of QDs for specific labeling cells and tissues depends on the bioconjugation. Santos et al., for example, reported the use of $\mathrm{CdS} / \mathrm{Cd}(\mathrm{OH})_{2}$ QDs functionalized with glutaraldehyde and conjugated to concanavalin-A (Con-A) lectin (Santos et al., 2006) to investigate cell alterations regarding carbohydrate profile in human mammary tissues diagnosed as fibroadenoma (benigne tumor). Con-A lectin is a protein which binds specifically to glucose/mannose residues expressed in the plasma membrane. Figure 7 shows the QD-Con-A more expressive staining of mammary tissue diagnosed with Fibroadenoma

Con-A was used also in another work for cellular labeling of Candida albicans with CdTe/CdS QDs conjugated or not to Con-A (Kato et al., 2012). Fluorescence microscopy analysis of the yeast cells showed that the non-functionalized QDs do not label C. albicans cells, however for the QD conjugated to Con-A the cells showed a fluorescence profile indicating that the cell wall was preferentially marked. 
In another work of the same group it was also used $\mathrm{CdS} / \mathrm{Cd}(\mathrm{OH})_{2}$ QDs functionalized with glutaraldehyde as efficient fluorescent labels for living human red blood cells (Santos et al., 2008a), the aim of this investigation was to determine the antigen-A expression in subgroups of group A erythrocytes.

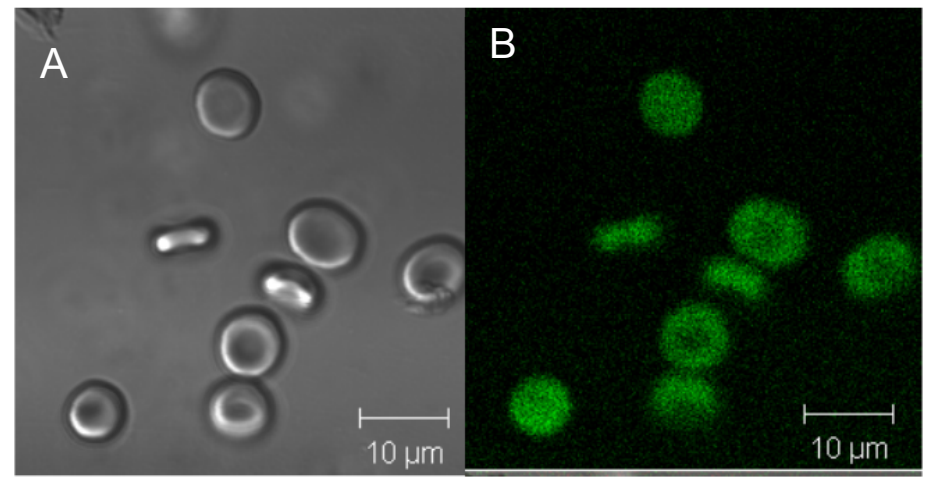

Figure 8. Microscopic confocal images obtained for QDs/anti-A marking living A+ erythrocytes. A is the DIC observation of the marked red blood cells and (B) is the marking pattern when excited at 488 nm (Santos et al., 2008a).

\subsubsection{Quantum dots for intracellular delivery}

QDs can be used as a probe for monitoring protein dynamics in live cells, allowing the study of their traffic down to a single molecule (Pinaud et al., 2010), taking advantages of the most striking properties as a fluorescent probe, which is long term imaging for prolonged periods of time (Courty et al., 2006). However, traffic of molecular dynamics, especially in live cells, are almost exclusively carried out for surface molecules - membrane proteins, accessible by the external side of the cells. This limitation arise mainly due to the incapacity of water dispersed QDs to cross the lipid bilayers by simple diffusion (only few works report tracking of intracellular molecules) (Chen \& Gerion, 2004).

a. Physical methods

The physical methods to deliver aqueous compounds into cells are of special interest since the precise control over the cell (extent of delivery over the population) and the amount of materials can be reached in most cases. These are mainly based on microinjection and electroporation. In fact these two traditional and well recognized methods are among the most efficient methods to deliver QDs into cells. The electroporation is based on the application of one or more strong electrical pulses, which is thought to create localized pores in the membrane bilayer for enhancing its permeability - Figure 9A. Using electroporation, Chen and Gerion delivered QDs into HeLa cells (Chen \& Gerion, 2004). The QDs were able to be recognized by the cellular machinery and enter the cell nucleus in living cells, although in a fraction of the total number of cells and as agglomerated particles. In fact, nanoparticle aggregates of up to $500 \mathrm{~nm}$ have been reported to be produced later after the application of electric pulses, even for protein- 
conjugated QDs. However, if agglomeration does not matter, as in the case of simple cell labeling, electroporation can be well suited. In fact, cells filled with QDs after electroporation can be readily seen in living mice for cell tracking purposes (Yoo et al., 2010).

Figure 9 shows schematic representations of the most common strategies for intracellular delivery of membrane-impermeable materials. Figure 9A and B represent physical processes while Fig. 9C and D are chemical methods. In electroporation, cells are exposed to an electric field and a single or multiple pulses are applied, creating pores that allow the passage of materials to the cell interior. In the microinjection (Figure 9B), a micropipette delivers precise amounts of fluids inside any compartment of the cells. In Fig. 9C, the conjugation of QDs with Cell Penetrating Peptides (CPPs) (discussed later) can deliver them into cells by direct membrane entrance (as shown in the scheme of Figure 9C) or by endocytosis. Also by endocytosis, polycation-coated QDs (green spheres) trigger "proton-sponge effect", (discussed later) releasing endo/lysosomal content into the cytosol. In Figure 9D, binding of negative cargos to lipoplex systems results in endocystosis likely due to charge interactions with negative plasma membrane. After internalization, charge neutralization seems to release the cargo from the lipid system.
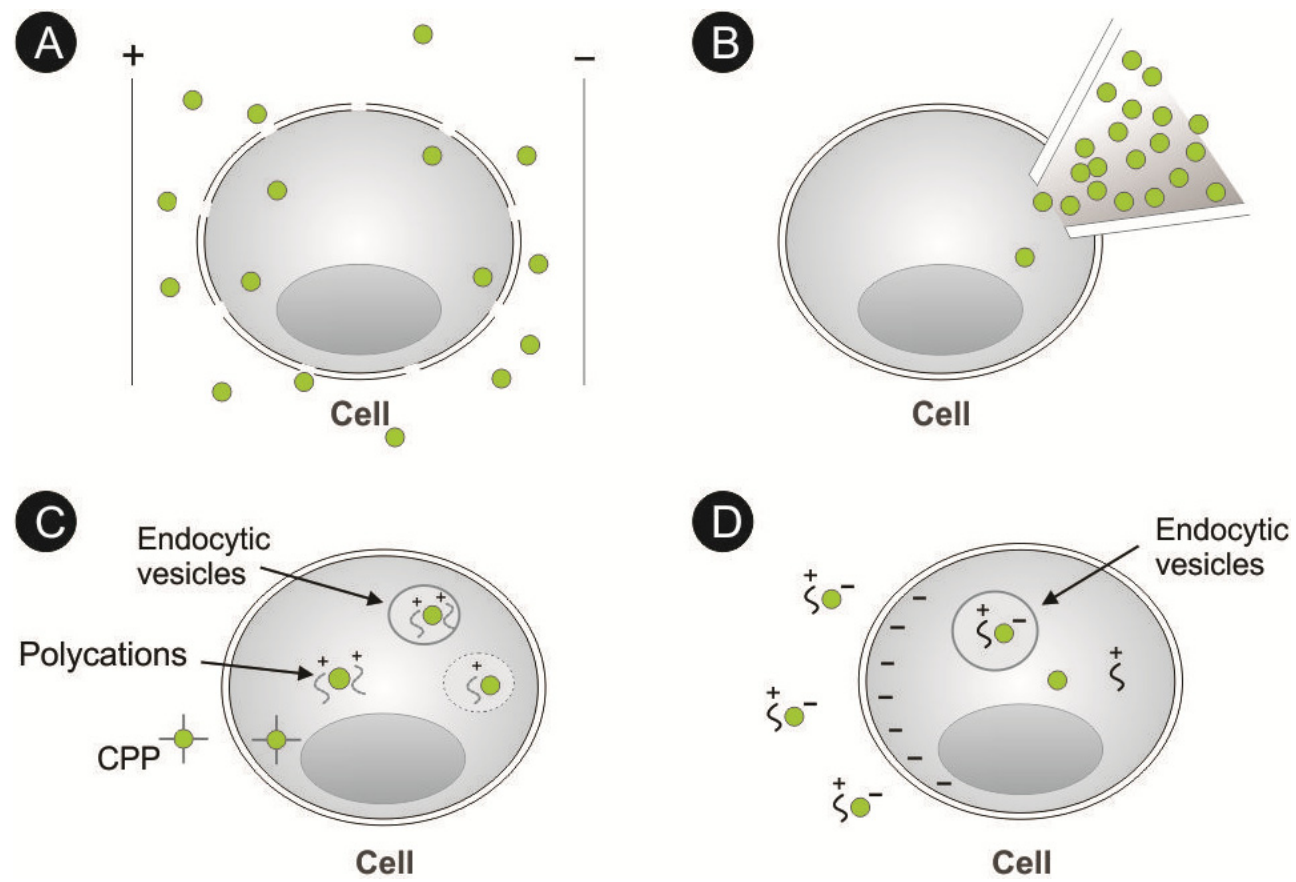

Figure 9. Schematic representations of four types of processes used in the internalization of QDs: electroporation (A); microinjection (B); CPP and polycation-mediated internalization (C) and lipoplex mediated process (D).

Another physical method for intracellular delivery of membrane impermeable materials is microinjection. This technique is based on the insertion of precise volumes inside an aqueous 
compartment (such a cell) by micropipettes - Figure 9B. Since the first attempts of using QDs as fluorescent probes, microinjection is recognized as a potent method to insert these particles in intracellular media. One example of the application of microinjection it is the use of micelle-capped QDs as an agent to follow the development of tissues derived from a single cell in living Xenopus embrios after transfection (Dubertret et al., 2002) or dynamics changes during the vasculature development in Zebrafish (Rieger et al., 2005).

Although their recognized efficiency, both methods suffer from some drawbacks. Electroporation not only cause QDs to aggregate, but may seriously compromise cellular viability. On the other hand, microinjection is technically and costly demanding, requiring specialized equipment and, as a serial technique it has poor statistical significance.

b. Chemical methods

Chemical approaches represent a wealthy range of strategies for intracellular delivery of membrane impermeable materials, and include covering cargos' surface or couple/bind them to a vehicle, promoting the labels enter into cytoplasm of a large number of cells simultaneously in a straightforward way. Moreover, it can actually be used in living animals the methods described above can only be used in such applications in very specific conditions.

Many methods to allow QDs to reach the cell cytosol are based on the conjugation of surface of nanoparticles to interact or to be recognized by cells until they reach the cytoplasm by different means. One of the most effective chemical methods for nanoparticle delivery into cells is the conjugation with Cell Penetrating Peptides (CPPs). A number of publications report such a class of molecules for this purpose, in which the mechanism of cell entry is similar to endocytosis (Thorén et al., 2004) rather than direct bypass through the lipid bilayer, although the consensus for the real pathway is still controversial. If trafficked into cells by endocytosis, these QDs bioconjugates need to be released from endo/lysosomal compartments to reach their targets (if such target is some intracellular organelles, for example).

A wide range of molecules can be conjugated to QDs' surface to be specifically delivered to cells (toxins, sugars, polymers and so on); however most of them lead to receptor-mediated endocytosis, which predominantly result in entrapment into endocytic vesicles. For this reason, we will not address here intracellular delivery of QDs by molecules which do not explicitly release these particles freely in cytosol.

Other chemical modifications can result in intracellular release after nanoparticle endocytosis rather than simple membrane permeation - as proposed for CPPs. One of such approaches is to cover QDs' surface with osmotic active polymers such as polyethyleneimine. After endocytosis, such polycations are capable of sequestering protons by $\mathrm{H}^{+}$-pumps in the endo/lysosomal membrane, which in turn force the entrance of $\mathrm{Cl}^{-}$ions and water to balance osmotic effects (this is the reason why this approach is called the "proton-sponge effect"). As a consequence, it leads vesicle rupture and releases endocytosed materials into the cell cytosol. Using this approach, Yezhelyev et al. delivered siRNA conjugated-QDs to breast cancer cells (Yezhelyev et al., 2008). The functionality of the system was showed by a 
remarked reduction in cyclophilin B protein expression after gene silencing. One similar approach is the osmotic lysis, where endo/lysosomal vesicles are also ruptured, now by submitting cells to hypotonic solutions. In fact, it was the method used to track for the first time an intracellular protein in living cells using QDs (Courty et al., 2006) where kinesin from Drosophila were delivered and tracked in HeLa cells. Lately, Nelson et al. reported a detailed study on the movement of Myosin Va (a molecular motor which tracks over actin filaments) inside COS-7 cells (Nelson et al., 2009). However, lysosome lysis might be harmful to cells as some acidic proteins such as proteases are released in the cytosol, which may degrade the constituents in there.

\section{c. Quantum dots encapsulation}

Quantum Dots can be entrapped in a vehicle for its delivery instead of being conjugated to transporter molecules, a strategy that can be also suited for intracellular delivery after endocytic uptake. It is quite advantageous because it allows the conjugation of targeting moieties (i.e. antibodies, ligands) on the surface of the nanoparticles, which was otherwise occupied by the targeting transporter molecules (as in the case of CPPs peptides and polymers). Moreover, it can avoid the rupture of acidic intracellular vesicles, which has the tendency to cause cytotoxicity effects. The encapsulating vehicles can be classified in two major groups, named polymeric and lipid delivering systems. QDs were encapsulated in functionalized polymeric poly(lactic-co-glycolic acid) (PLGA) nanospheres and delivered into the cell cytosol after endocytosis of the complex (Kim et al., 2008). After preferential endocytosis of antibody-coated polymer nanospheres into ErbB2 over expressing cancer cells, the polymer were degraded in the acidic intracellular compartments releasing the bioconjugated QDs, which in turn could reach and label intracellular structures such as mitochondria and actin filaments.

Another approach is using micelles. An advantage of encapsulating QDs in lipid micelles relies on the small size of the resulting probe, up to $25 \mathrm{~nm}$ (Carion et al., 2007). Taking advantages on the physical-chemical and photostability of these QD-containing micelles, the group who reported this system for the first time could track cell lineage developments in live Xenopus embrios (Dubertret et al., 2002). This breakthrough report was one of the first reports on the use of QDs for in vivo imaging.

Among the vehicles composed of lipids, probably the most popular is liposomes (Valenzuela, 2007; Al-Jamal \& Kostarelos, 2007). Liposomes are lipid vesicles containing one (or more) lipid bilayer(s) enclosuring an aqueous compartment and that can entrap hydrophilic and/or hydrophobic materials during its formation (Valenzuela, 2007). As in the case of micelles (or any other encapsulation system), their interaction with biological species depends on the physical-chemical properties, which can be fine-tuned. In fact, Yang et al. (Yang et al., 2009) encapsulated water aqueous CdTe QDs in folate-conjugated liposomes and showed that these vesicles can be directed to folate-overexpressing cancer cells and be monitored by QDs fluorescence. The resulting system is resistant to optical and chemical degradation, with lower toxic effects.

QDs can also be delivered to cells by commercial cationic liposomes, the lipofection system (Fig. 9D). Lipoplex are positively-charged lipidic vesicles (mainly liposomes) able to bind 
negative particles, including oligonucleotides and QDs, which mediate charge interactions with cells, leading to endocytosis of the resulting system and eventually the release of cargos inside the cell. In such an application, Yoo et al. (Yoo et al., 2008) reported for the first time the use of these lipid vesicles as QD vehicles for protein tracking inside living cells. In contrast to earlier works, their bioconjugated QDs could escape from cellular vesicles and reach the cytosol, where they could be used to track the movements of actin, kinesin and tubulin proteins. Although the mechanism of endossomal release of materials delivered by cationic liposomes is not known, it is believed that charges play important roles in membrane destabilization, which could explain the successfully applications of such liposomes. However cytosolic release is not the main fate of delivered moieties in most applications of cationic liposomes, as exemplified above. It is important to note that lipofection delivery is not based on encapsulation; it is rather based on electrostatic interactions with negatively-charged cargos.

\subsection{Quantum dots as probes in other bioassays}

An increasing interest in using QDs as more than passive/active labels is reflected by the great number of published data in the literature in the past decade. There is a growing research community that recognizes that the fluorescent QDs may be extensively applied as a central component of nano-probes (Algar \& Krull, 2008). We may classify among all the suggested applications the following: Fluorescence Resonance Energy Transfer (FRET) for bioassays, optical biosensors and Photodynamic Therapy (PDT).

In all these applications, the QDs act as scaffolds for the assembly of biomolecular probes while its fluorescence is modulated by biorecognition events. In the particular case of FRETQDs studies, a broad absorption band combined with a size-tunable fluorescence and larger physical size (when compared to conventional dyes) allow: (i) optimization of the spectral overlap with any potential FRET acceptor; (ii) excitation at a wavelength far from the acceptor absorption peak (minimizing acceptor direct excitation); QDs can be excited over a range of wavelengths in the blue-ultraviolet region of the spectrum to allow minimization of the direct excitation of acceptors and (iii) the ability to assemble multiple acceptors around a QD core to increase the overall FRET efficiency (Algar \& Krull, 2008; Bakalova et al., 2004; Juzenasa et al., 2008; Medintz \& Mattoussi, 2009; Tekdas et al., 2012). The use of fluorescence resonance energy transfer (FRET) as a mechanism of tuning QDs' fluorescence is particularly advantageous and due to their high photostability QDs are ideal donors (Algar \& Krull, 2008; Bakalova et al., 2004; Medintz \& Mattoussi, 2009). Moreover, the potentially high quantum yield of QDs helps to maximize Förster distances, while the narrow emission can be tuned to optimize spectral overlap and reduce crosstalk between donor and acceptor (Algar \& Krull, 2008; Medintz \& Mattoussi, 2009).

The great potential of FRET-QDs applications may be exemplified by several reports. For instance, Stringer et al. developed a biosensor that is able to detect troponin I to diagnose early injuries of cardiac muscles (Stringer et al., 2008) and also to detect small amounts of nitrated ceruloplasmin (a significant biomarker for cardiovascular disease, lung cancer, and 
stress response to smoking) (Pyo \& Yoo, 2012). Another interesting application is described by Krull et al. which performed solid-phase hybridization assays aiming multiplexed nucleic acid diagnostics using QDs as donors in FRET processes (Algar \& Krull, 2008; Medintz \& Mattoussi, 2009). They developed multiplexed assays using immobilized QDs as both FRET donors and scaffolds for the immobilization of oligonucleotides probes, where the association of fluorescent acceptor dyes with sequence-specific hybridization events provided the basis for transduction. QD donors were paired with one or more acceptor dyes, and the ratios of QD fluorescence and FRET-sensitized acceptor fluorescence provided an analytical signal. The basic idea is depicted in Figure 10.

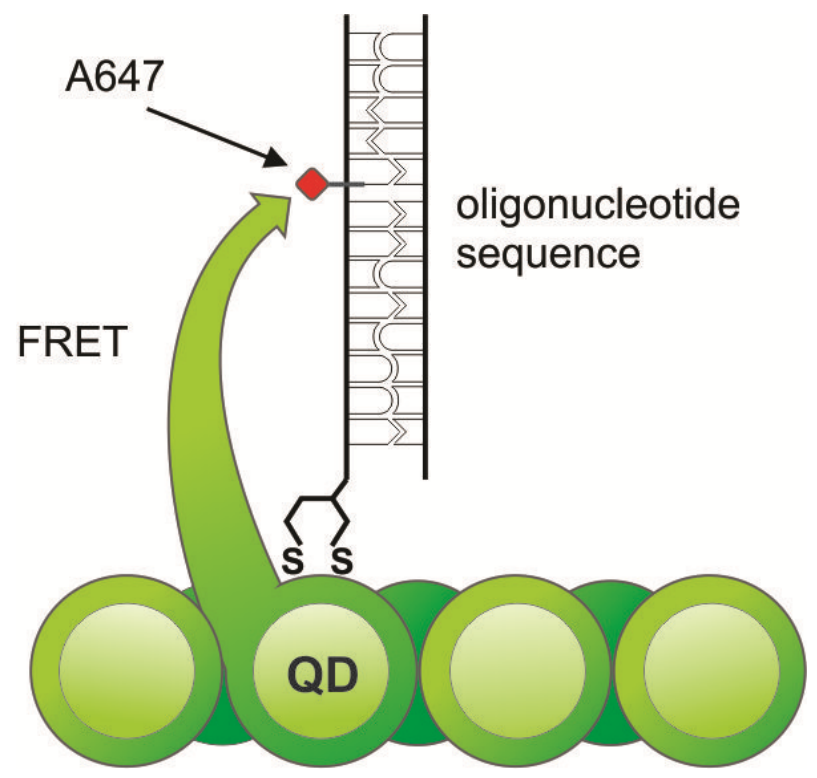

Figure 10. Schematic representation of a FRET process. Immobilized QDs are derivatized with dithiolterminated probe oligonucleotides and under light excitation the QDs are envolved in the emission of the Alexa Fluor 647 dye bound to a determined oligonucleotides sequence (Algar \& Krull, 2008; Medintz \& Mattoussi, 2009).

QDs may also play a critical role as energy acceptors in bioluminescence resonance energy transfer (BRET) processes, with a bioluminescent protein as the energy donor. BRET resembles FRET in many aspects except that it does not require external light source for the donor excitation. The broad excitation spectra and large Stokes shift of QDs allow them to be excited by nearly all the bioluminescent proteins in BRET assemblies. Feasibility of QDs as the BRET acceptor for a mutant of Renilla luciferase (Luc8 with improved chemical stability and light efficiency) has been recently realized both in vitro and in vivo (Samia et al., 2006).

More recently QDs have also been applied in photodynamic therapy (PDT) related processes (Juzenasa et al., 2008). This could be done due to the combination of the unique optical properties of these nanostructured systems with their active chemical surfaces. PDT 

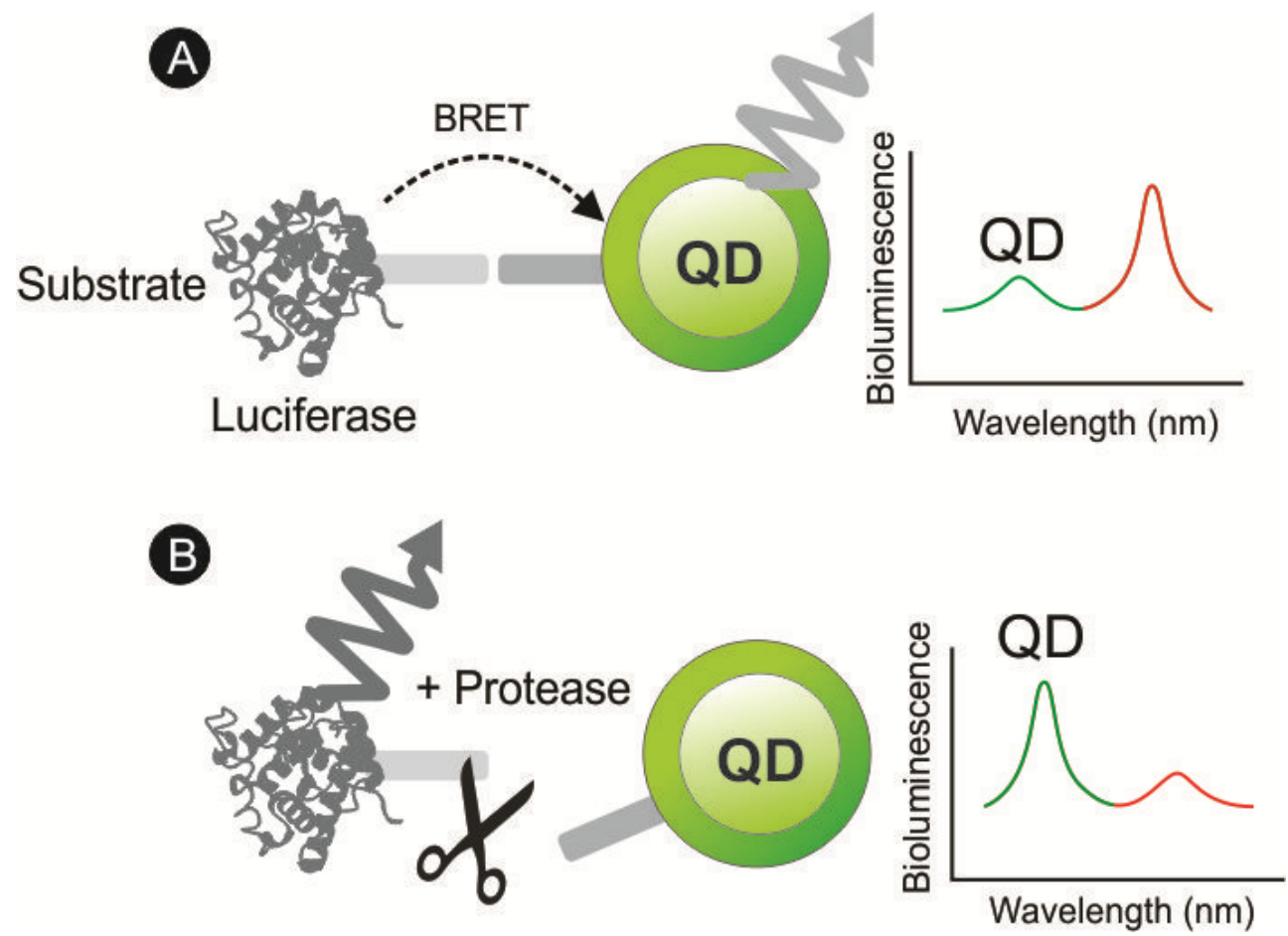

Figure 11. Schematic representation of BRET-QDs sensor applied to detect protease activity. In this assembly QD and luciferase protein are closely linked together through a peptide substrate. In process (A) QD fluorescence induced by the BRET process is observed and in the presence of a protease (B) the BRET process is disrupted leading to a loss of bioluminescence-induced QD emission (Xia \& Rao, 2009).

causes cell death (by necrosis or apoptosis) when singlet oxygen and other reactive species of oxygen (ROS) are produced while photosensitizers are stimulated by light. In PDT studies QDs may work as energy donors for traditional photosensitizers or interacting directly with molecular oxygen by mechanisms of energy transfers to generate singlet oxygen as described in Figure 12. PDT based QDs have been used both for treatment of skin lesions and for the treatment of skin cancers (Xia \& Rao, 2009). QDs conjugated with Pc4, a known photosensitizing protein, were excited at $488 \mathrm{~nm}$ and by energy transfer mechanisms the protein was excited indirectly, emitting at $680 \mathrm{~nm}$. In other words, the QDs, when excited, emit in a wavelength which excites the protein (Xia \& Rao, 2009).

\section{Some drawbacks of quantum dots}

Non-specific interactions are a common phenomenon on the application of biological probes. Besides some benefits, these interactions are commonly a negative feature. An incomplete conjugation may result in residual non-conjugated QDs in the same colloidal suspension which can bind or interact non-specifically with the biological system and interfere in the desired results interfering in the specificity of the original applications. 


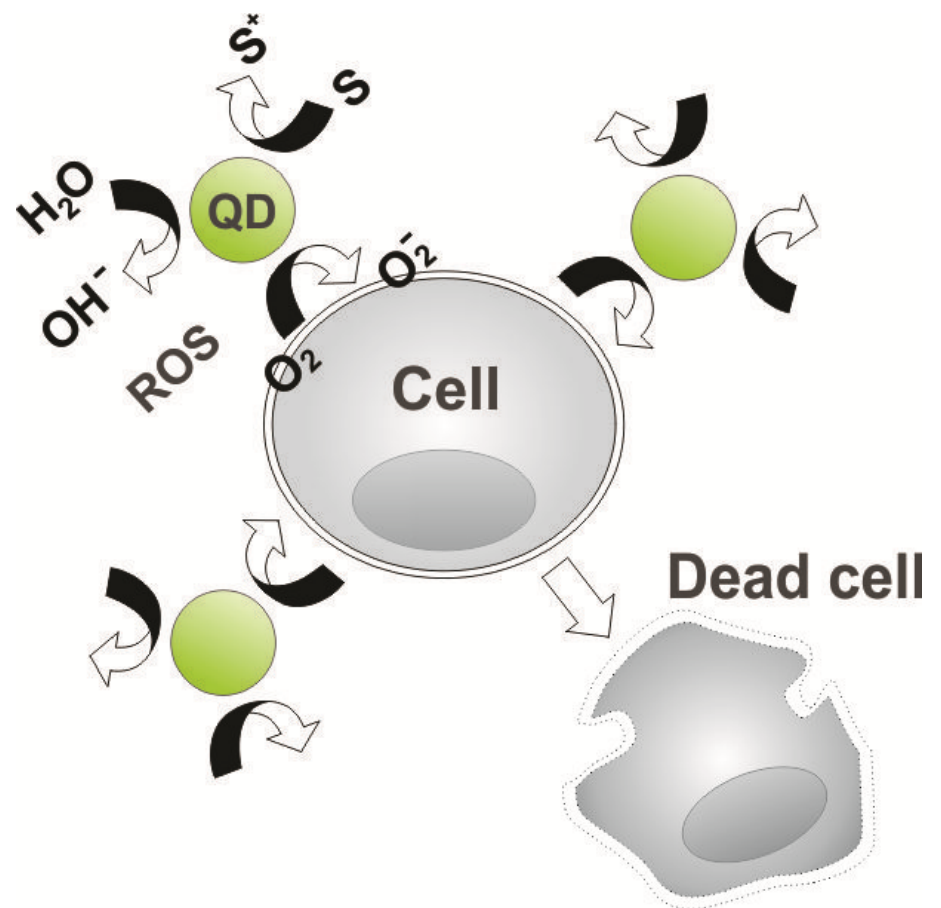

Figure 12. The basic process in the production of ROS species in cell PDT using QDs as producers of $\mathrm{O}_{2}^{-}$.

The most common strategy to overcome non-specific labelling relies in covering the QDs surface with polar polymer molecules, such as polyethylene glycol (PEG). This is because such polymers are biologically "inert" and hinder electrostatic interactions of nanoparticle surface against cell surface or molecules in suspension Pegylated nanoparticles are therefore less prone to aggregation (that is, much more stable) and virtually binding-free. Moreover, they can allow further conjugation with functional biomolecules, include proteins and antibodies (Hezinger et al., 2007; Medintz et al., 2005). Pegylated bioconjugated QDs are then able to bind specifically their targets, being stable and virtually free of non-specific interactions. Pegylation, however, is not universally inert. We have demonstrated that PEGcoated $\mathrm{CdS} / \mathrm{Cd}(\mathrm{OH})_{2}$ QDs are able to bind live parasites cells, triggering endocytosis by specialized endocytic pathways such as those using the flagellar pocket (Chaves et al., 2008).

Understanding the interactions of nanoparticles and biological specimens, specially cells, is of great interest since one can therefore modulate specific cellular processes. Unrestricted interactions of any kind of materials, including QDs, have the potential to be toxic, especially at higher concentration and/or with enhanced adsorption/internalization. Beyond the changes over cell function, more evident effects are prone to be caused by QDs, including cellular ones such: (i) changes in cell morphology (Chang et al., 2009), (ii) oxidative stress (Lovrić, et al., 2005), (iii) release of heavy metal compounds (Kirchner et al., 2005) and (iv) genetic and epigenetic damage (Choi et al., 2008), as well as local inflammation in live rats, as we have recently reported. 


\section{General conclusions}

QDs have broad and strong one-photon absorption, narrow and symmetric size-tunable fluorescence bands, and a great resistance to photobleaching, making them an attractive alternative to molecular fluorophores in imaging applications and bioanalytical chemistry assays. This Chapter discusses some current applications of QDs as well as presents some drawbacks that still remain. Taken together, all these findings show that a deeper understanding of the mechanisms underlying QDs-biological systems interactions is helpful in the way that researchers can avoid side effects and improve the quality of labeling of QDs for diagnostics and therapeutic purposes.

\section{Author details}

Adriana Fontes, Rafael Bezerra de Lira, Maria Aparecida Barreto Lopes Seabra, Thiago Gomes da Silva, Antônio Gomes de Castro Neto and Beate Saegesser Santos Biomedical Nanotechnology research group of the Universidade Federal de Pernambuco, Recife, Pernambuco, Brazil

\section{Acknowledgement}

The authors are grateful to CAPES, CNPq, FACEPE, HEMOPE, L'óreal, Brazilian Academy of Sciences and UNESCO. This work is also linked to the National Institute of Photonics (INCT-INFO). The authors also wish to thank Pedro Barroca for the schematic drawings.

\section{References}

Algar, W. R.; Krull, U. J. (2008) Quantum Dots as Donors in Fluorescence Resonance Energy Transfer for the Bioanalysis of Nucleic Acids, Proteins, and Other Biological Molecules. Anal. Bioanal. Chem., Vol. 391, pp. 1609-1618.

Algar, W. R.; Tavares, A. J.; Krull, U. J. (2010) Beyond Labels: A Review of the Application of Quantum Dots as Integrated Components of Assays, Bioprobes, and Biosensors Utilizing Optical Transduction. Anal. Chim. Acta, Vol. 673, pp. 1-25.

Al-Hajaj, N.A., Moquin, A., Neibert, K.D., Soliman, G.N., Winnik, F.M., Maysinger, D. (2011) Short Ligands affect Modes of QD uptake and elimination in Human Cells. ACS Nano, Vol.6, pp.4909-4918.

Al-Jamal, W. T.; Kostarelos, K. (2007) Liposome-nanoparticle hybrids for multimodal diagnostic and therapeutic applications. Nanomedicine, Vol. 2, pp. 85-98.

Bakalova, R.; Ohba, H.; Zhelev, Z.; Ishikawa, M.; Baba, Y. (2004) Quantum dots as photosensitizers? Nature Biotechnology, Vol. 22, pp. 1360-1361.

Biju, V.; Itoh, T.; Ishikawa, M. (2010) Delivering quantum dots to cells: bioconjugated quantum dots for targeted and nonspecific extracellular and intracellular imaging. Chem. Soc. Rev., Vol. 39, pp. 3031-3056. 
Brus, L. E. (1984). Electron-electron and electron-hole interactions in small semiconductor crystallites-the size dependence of the lowest excited electronic state. Journal of Chemical Physics, Vol. 80, pp. 4403-4409.

Cai, W.; Shin D.-W.; Chen, K.; Gheysens, O.; Cao. Q; Wang, S. X.; Gambhir; S. S. Chen, X. (2006) Peptide-Labeled Near-Infrared Quantum Dots for Imaging Tumor Vasculature in Living Subjects. Nano Lett., Vol. 6, pp 669-676.

Carion, O.; Mahler, B.; Pons, T.; Dubertret, B. (2007) Synthesis, encapsulation, purification and coupling of single quantum dots in phospholipid micelles for their use in cellular and in vivo imaging. Nature Protocols, Vol. 2, pp. 2383-2390.

Chang, S. Q.; Dai, Y. D.; Kang, B.; Hana, W.; Mao, L.; Chen, D. (2009) UV-enhanced cytotoxicity of thiol-capped CdTe quantum dots in human pancreatic carcinoma cells. Toxicology Letters, Vol. 188, pp. 104-111

Chaves, C. R.; Fontes, A.; Farias, P. M. A.; Santos, B. S.; Menezes, F. D.; Ferreira, R. C.; Cesar, C. L.; Galembeck, A.; Figueiredo, R. C. B. Q. (2008) Application of core-shell PEGylated $\mathrm{CdS} / \mathrm{Cd}(\mathrm{OH})_{2}$ quantum dots as biolabels of Trypanosoma cruzi parasites. Applied Surface Science, Vol. 255, pp. 728-730.

Chen, F.; Gerion, D. (2004) Fluorescent CdSe/ZnS Nanocrystal-Peptide Conjugates for Longterm, Nontoxic Imaging and Nuclear Targeting in Living Cells. Nano Letters, Vol. 4, pp. $1827-1832$.

Choi, A. O.; Brown, S. E.; Szyf, M.; Maysinger, D. (2008) Quantum dot-induced epigenetic and genotoxic changes in human breast cancer cells. J Mol Med, Vol. 86, pp. 291-302.

Conroy, J.; Byrne, S. J.; Gun'ko, Y. K.; Rakovich, Y. P.; Donegan, J. F.; Davies, A.; Kelleher, D.; Volkov, V., (2008) CdTe Nanoparticles Display Tropism to Core Histones and Histone-Rich Cell Organelles. Small, Vol. 4, pp. 2006-2015.

Courty, S.; Luccardini, C.; Bellaiche, Y.; Cappello, G.; Dahan, M. (2006) Tracking Individual Kinesin Motors in Living Cells Using Single Quantum-Dot Imaging. Nano Letters. Vol. 6, pp. 1491-1495.

Dabbousi, B. O.; Rodriguez, V. J.; Mikulec, F. V.; Heine, J. R.; Mattoussi, H.; Ober, R. (1997). (CdSe) ZnS core-shell quantum dots: synthesis and characterization of a size series of highly luminescent nanocrystallites. Journal of Physical Chemistry B, Vol. 101, pp. 9463-9475.

Dubertret, B.; Skourides, P.; Norris, D. J.; Noireaux, V.; Brivanlou, A. H.; Libchaber, A. (2002) In Vivo Imaging of Quantum Dots Encapsulated in Phospholipid Micelles. Science, Vol. 298, pp. 1759-1762.

Farias, P. M. A.; Santos, B. S.; Menezes, F. D.; Ferreira, R.; Fontes, A.; Carvalho H. F.; Romão L.; Moura-Neto, V.; Amaral, J. C. O. F.; Cesar, C. L.; Figueiredo, R. C. B. Q.; Lorenzato, F. R. B. (2006) Quantum dots as fluorescent bio-labels in cancer diagnostic. Phys. Stat. Sol. (C), Vol. 3, pp. 4001-4008.

Gao, J.; Chen, X.; Cheng, Z. (2010) Near-infrared quantum dots as optical probes for tumor imaging. Curr. Top Med Chem., Vol. 10, pp. 1147-1157.

Ghinea, N; Simionescu, N. (1985) Anionized and Cationized Hemeundecapeptides as Probes for Cell Surface Charge and Permeability Studies: Differentiated Labeling of Endothelial Plasmalemmal Vesicles. The Journal Of Cell Biology Volume, Vol. 100, pp. 606-612. 
Goldman, E. R.; Anderson, G. P.; Tran, P. T.; Mattoussi, H.; Charles, P. T.; Mauro, J. M. (2002) Conjugation of Luminescent Quantum Dots with Antibodies Using an Engineered Adaptor Protein To Provide New Reagents for Fluoroimmunoassays. Anal. Chem., Vol. 74, pp. 841-847.

Jaiswal, J. K.; Matoussi, H.; Mauro, J. M.; Simon, S.; (2003). Long-Term Multiple Color Imaging Of Live Cells Using Quantum Dot Bioconjugates. Nature Biotechnology, Vol. 21, pp. 47-51.

Jiang, W.; Kim, Y.; Rutka, S. B. J. T.; Chan, W. C. W. (2008) Nanoparticle-mediated cellular response is size-dependent. Nature Nanotechnology, Vol. 3, pp. 145-150.

Juzenas, P.; Chen, W.; Sun, Y. P.; Coelho, M. A. N.; Generalov, R.; Generalova, N.; Christensen, I. L. (2008) Quantum dots and nanoparticles for photodynamic and radiation therapies of cancer. Advanced Drug Delivery Reviews, Vol .60, pp. 1600-1614.

Kato, I. T.; Santos, C. C.; Benetti, E.; Tenorio, D. P. L. A.; Cabral Filho, P. E.; Sabino, C. P.; Fontes, A.; Santos, B. S.; Prates, R. A.; Ribeiro, M. S. CdTe/CdS-MPA quantum dots as fluorescent probes to label yeast cells: synthesis, characterization and conjugation with Concanavalin A. (2012) Photonics West, San Francisco. Proceedings of SPIE - Colloidal Nanocrystals for Biomedical Applications VII, Vol. 8232, pp. 82320D.

Kim, B. Y. S.; Jiang, W.; Oreopoulos, J; Yip, C. M.; Rutka, J. T.; Chan, W. C. W. (2008) Biodegradable Quantum Dot Nanocomposites Enable Live Cell Labeling and Imaging of Cytoplasmic Targets. Nano Letters, Vol. 8, pp. 3887-3892.

Kirchner, C.; Liedl, T.; Pellegrino, S. K. T.; Javier, A. M.; Gaub, H. E.; Stölzle, S.; Fertig, N.; Parak, W. J. (2005) Cytotoxicity of Colloidal CdSe and CdSe/ZnS Nanoparticles. Nano Letters, Vol. 5, pp. 331-338

Lira, R. B.; Cavalcanti, M. B.; Seabra, M. A. B. L.; Silva, D. C. N.; Amaral, A. J.; Santos, B. S.; Fontes, A. (2012) Non-specific interactions of CdTe/Cds Quantum Dots with human blood mononuclear cells. Micron, Vol. 43, pp. 621-626.

Liu, W.; Howarth, M.; Greytak, A. B.; Zheng, Y.; Nocera, D. G.; Ting, A. Y.; Bawendi, M. G. (2008) Compact Biocompatible Quantum Dots Functionalized for Cellular Imaging. J. Am. Chem. Soc., Vol. 130, pp. 1274-1284.

Liu. W.; Zhang, S.; Wang, L.; Qu, C.; Zhang, C.; Hong, L.; Yuan, L.; Huang, Z.; Wang, Z.; Liu, S.; Jiang, G. (2011) CdSe Quantum Dot (QD)-Induced Morphological and Functional Impairments to Liver in Mice. PLoS ONE, Vol. 6, e24406. doi:10.1371/journal.pone.0024406.

Lovrić, J.; Bazzi, H. S.; Cuie, Y.; Fortin, G. R. A; Winnik, F. M.; Maysinger, D. (2005) Differences in subcellular distribution and toxicity of green and red emitting CdTe quantum dots. J Mol Med, Vol. 83, pp. 377-385.

Ma-Hock, L.; Brill, S.; Wohlleben, W.; Farias, P. M. A.; Chaves, C. R.; Tenório, D. P. L. A.; Fontes, A.; Santos, B. S.; Landsiedel, R.; Strauss, V.; Treumann, S.; van Ravenzwaay, B. (2012) Short term inhalation toxicity of a liquid aerosol of $\mathrm{CdS} / \mathrm{Cd}(\mathrm{OH})_{2}$ core shell quantum dots in male Wistar rats. Toxicology Letters, Vol. 208, pp. 115-124.

Medintz, I. L.; Mattoussi, H. (200) Quantum Dot-Based Resonance Energy Transfer and Its Growing Application in Biology. Phys. Chem. Chem. Phys., Vol. 11, pp. 17-45. 
Medintz, I. L.; T. Uyeda, H.; Goldman, E. R.; Mattoussi, H. (2005) Quantum dot bioconjugates for imaging, labelling and sensing. Nature Materials, Vol. 4, pp. 435-446.

Menezes, F. D. de; Brasil Jr., A. G.; Moreira, W. L.; Barbosa, L. C.; Cesar, C. L.; Ferreira, R. C. de; Farias, P. M. A. de; Santos, B. S. (2005). CdTe/CdS core shell quantum dots for photonic applications, Microelectronics Journal, Vol. 36, pp. 989-991.

Nelson, S.R.; Ali, M.Y.; Trybus, K.M.; Warshaw, D.M. (2009) Random walk of processive, quantum dot-labeled myosin Va molecules within the actin cortex of COS-7 cells. Biophys J., Vol. 97, pp. 509-518.

Nichols, B. J. (2003a). Caveosomes and endocytosis of lipid rafts. J. Cell Sci., Vol. 116, pp. 4707-4714.

Nichols, B. J. (2003b). GM1-containing lipid rafts are depleted within clathrin-coated pits. Curr. Biol., Vol. 13, pp. 686-690.

Noh, Y.-W.; Lim, Y. T.; Chung, B. H. (2008) Noninvasive imaging of dendritic cell migration into lymph nodes using near-infrared fluorescent semiconductor nanocrystals. The FASEB Journal, Vol. 22, pp. 3908-3918.

Pinaud F.; Clarke S.; Sittner, A.; Dahan, M. (2010) Probing cellular events, one quantum dot at a time. Nature Methods, Vol. 7, pp. 275-285.

Pyo, D., Yoo, J. (2012) New Trends in Fluorescence Immunochromatography. J. Immunoassay and Immunochemistry, Vol. 33, pp. 203-222.

Rieger, S.; Kulkarni, R. P.; Darcy, D.; Fraser S. E.; Koster, R. W. (2005) Quantum Dots Are Powerful Multipurpose Vital Labeling Agents in Zebrafish Embryos. Developmental Dynamics, Vol. 234 pp. 670-681.

Samia, A. C. S.; Dayal, S.; Clemens, B. (2006) Quantum Dot-based Energy Transfer: Perspectives and Potential for Applications in Photodynamic Therapy. Photochemistry and Photobiology, Vol. 82, pp. 617-625.

Santos, B. S., Farias, P. M. A. ; Fontes, A. . Semiconductor Quantum Dots for Biological Applications. In: Mohamed Henine (Editor Chefe). (Org.). Handbook of Self Assembled Semiconductor Nanostructures Novel Devices in Photonics and Electronics. Amsterdam: Elsevier, 2008a, p. 773-798.

Santos, B. S.; Farias, P. M. A.; Menezes, F. D.; Brasil Jr, A. G.; Fontes, A.; Romão, L.; Amaral, J. O.; Moura-Neto, V.; Tenório, D. P. L. A.; Cesar, C. L.; Barbosa, L. C.; Ferreira, R. (2008b) New highly fluorescent biolabels based on II-VI semiconductor hybrid organicinorganic nanostructures for bioimaging. Applied Surface Science, Vol. 255, pp. 790792.

Santos, B. S.; Farias, P. M. A. ; Menezes, F. D. ; Ferreira, R. C.; Alves Junior, S.; Figueiredo, R. C. B. Q.; Carvalho Junior, L. B.; Beltrão, E. I. C. (2006) CdS-Cd(OH)2 core shell quantum dots functionalized with Concanavalin A lectin for recognition of mammary tumors. Physica Status Solidi. C, Conferences and Critical Reviews, Vol. 3, pp. 4017-4022.

Stringer, R. C.; Hoehn, D.; Grant, S. A. (2008) Quantum Dot-Based Biosensor for Detection of Human Cardiac Troponin I Using a Liquid-Core Waveguide. Sensors Journal, IEEE, Vol. 8, pp. 295-300.

Tekdas, D. A.; Durmus, M.; Yanıka, H.; Ahsen V., (2012) Photodynamic therapy potential of thiol-stabilized CdTe quantum dot-group 3Aphthalocyanine conjugates (QD-Pc) 
Spectrochim Acta Part A: Molecular and Biomolecular Spectroscopy, Vol. 93, pp. 313320

Valenzuela, S., Liposome techniques for synthesis of biomimetic lipid membranes in Ferrari, M.; Martin, D. (Eds). Nanobiotechnology of biomimetic membranes, , New York: Springer, 2008 p. 75-87.

Verma, A.; Stellacci, F. (2010) Effect of Surface Properties on Nanoparticle-Cell Interactions. Small, Vol. 6, pp. 12-21.

Williams, Y.; Sukhanova, A.; Nowostawska, M.; Davies, A. M.; Mitchell, S.; Oleinikov, V.; Gun'ko, Y.; Nabiev, I.; Kelleher, D.; Volkov, Y. (2009) Probing Cell-Type-Specific Intracellular Nanoscale Barriers Using Size-Tuned Quantum Dots. Small, Vol. 5, pp. 2581-2588.

Xia, Z., Rao, J. (2009) Biosensing and imaging based on bioluminescence resonance energy transfer. Current Opinion in Biotechnology, Vol. 20, pp. 1-8.

Yang, C., Ding, N.; Xu, Y.; Qu, X.; Zhang, J.; Zhao, C.; Hong, L.; Lu, Y.; Xiang, G. (2009) Folate receptor-targeted quantum dot liposomes as fluorescence probes. Journal of Drug Targeting, Vol. 17, pp. 502-511.

Yeh, C. Y.; Lu, Z. W.; Froyen, S.; Zunger, A. (1992). Zinc-blende-wurtzite polytypism in semiconductors. Physical Review B, Vol. 46, pp. 10086-10097.

Yezhelyev, M. V.; QI, L.; O’Regan, R. M.; Nie, S.; Gao, X. (2008) Proton-Sponge Coated Quantum Dots for siRNA Delivery and Intracellular Imaging. J. Am. Chem. Soc., Vol. 130, pp. 9006-9012.

Yin, Y.; Alivisatos, A. P. (2005) Colloidal nanocrystal synthesis and the organic-inorganic interface. Nature, Vol. 437, pp. 664-670.

Yoo, J. S.; Won, N.; Kim, H. B.; Bang, J.; Kim, S.; Ahn, S.; Soh, K. S. (2010) In vivo imaging of cancer cells with electroporation of quantum dots and multispectral imaging. Journal of Applied Physics, Vol. 107, pp. 124702-124710.

Yoo, J.; Kambara, T.; Gonda, K.; Higuchi, H. (2008) Intracellular imaging of targeted proteins labeled with quantum dots. Experimental Cell Research, Vol. 314, pp. 3563-3569. 